\title{
Providers' and key opinion leaders' attitudes, beliefs, and practices concerning emergency contraception: A multicountry study in India, Nigeria, and Senegal
}

\author{
Martha Brady \\ Population Council \\ M.E. Khan \\ Population Council \\ Babatunde A.O. Ahonsi \\ Population Council \\ Babacar Mane \\ Population Council \\ Ian Askew \\ Population Council
}

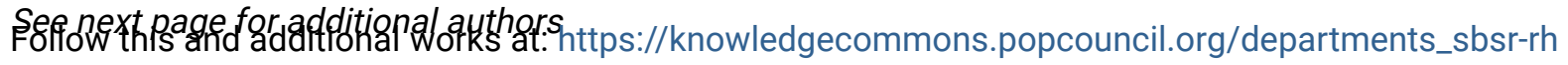

Part of the International Public Health Commons, Public Health Education and Promotion Commons, Social and Behavioral Sciences Commons, and the Women's Health Commons How does access to this work benefit you? Let us know!

\section{Recommended Citation}

Brady, Martha, M.E. Khan, Babatunde A. O. Ahonsi, Babacar Mane, Ian Askew, and Saumya RamaRao. 2012. "Providers' and key opinion leaders' attitudes, beliefs, and practices concerning emergency contraception: A multicountry study in India, Nigeria, and Senegal," program brief. New York: Population Council. 


\section{Authors}

Martha Brady, M.E. Khan, Babatunde A.O. Ahonsi, Babacar Mane, Ian Askew, and Saumya RamaRao 
Improving knowledge of and access to reproductive health technologies is critical to improving women's health. While major gains have been made over the past several decades, barriers to access remain in many places of the world. Contraceptive technologies that enhance women's ability to exercise control over their reproductive lives are particularly important; emergency contraception is one such example.

Emergency contraception (EC) has been in use for more than 30 years, is available in many countries, exists in multiple formulations, and is offered through a range of service delivery points. $E C$ is an effective and safe method of preventing pregnancy, and its provision of postcoital protection gives it a unique role in the contraceptive mix within family planning programs.

Currently, three types of emergency contraception exist: (1) dedicated emergency contraceptive pill (ECP) products, including levonorgestrel-only pills and ulipristal acetate; (2) conventional oral contraceptive pills taken in a specific timing and dosage sequence (known as the Yuzpe method); and (3) the insertion of a copper intrauterine device (IUD). The IUD has not been used to any extent as EC in the developing world at this point.

\section{BACKGROUND}

Dedicated ECP products are registered in countries throughout the world, and many countries have more than one registered ECP product. More than 60 countries provide ECP through pharmacies. The Yuzpe method is used in settings where no dedicated ECP products are available, and/or where economic and service barriers prohibit women from obtaining them. Although this type of off-label use of oral contraceptives is an important option for women, a dedicated product-one that is packaged and labeled specifically for emergency contraceptive use and made available through a range of outlets (clinics, pharmacies, hospitals, women's shelters, workplaces)-could potentially improve access and use. In theory ECP is widely available; in practice, however, procurement, financing, and distribution mechanisms for dedicated ECP commodities are not well established in many settings, thereby limiting availability and resulting in an underutilized option for pregnancy prevention.

\section{BARRIERS TO ACCESS FOR WOMEN: POLI- CIES, PROVIDERS, AND HEALTH SYSTEMIS}

Research indicates a number of influences on women's access to ECP. Access is most severely affected in countries where contextual and systems-level barriers converge to restrict provision and use of ECP. The following barriers have been noted across diverse settings: (1) lack of favorable government policy; (2) misinformed policymakers 
and providers; (3) undefined and inadequate service delivery systems; and (4) stringent prescription requirements. Further, awareness of emergency contraception and the sources of supply for ECP is limited among potential users.

Role of providers and key opinion leaders Although women's access to ECP is constrained by many factors, providers and key opinion leaders (KOLs) play a key role in ensuring its availability and enhancing access to the product. Providers' lack of accurate information and training in ECP, coupled with negative attitudes and misconceptions about the method, directly affect their provision practices and, in turn, women's access. Key opinion leaders, who include a range of influential individuals (e.g., senior Ministry of Health officials, leaders of medical and pharmacy associations, civil society representatives, religious and other social leaders, donors, etc.), also play a critical role in shaping public opinion and influencing policy.

\section{WIDENING THE LENS AND DEEPENING THE FOCUS ON PROVIDERS AND KEY OPINION LEADERS}

Recognizing the critical role these two stakeholder groups play in fostering or impeding access, the Population Council conducted a cross-sectional, descriptive, multicountry study in India, Nigeria, and Senegal aimed at understanding the attitudes, beliefs, and practices of providers and key opinion leaders regarding the provision and use of EC. This study represents the first systematic inquiry of KOLs in these three countries, which have considerably different social and policy environments.

\section{India}

In India, ECP is included in the National Family Planning Program and, theoretically, is available at government health and family planning facilities. Because many doctors and paramedics have not been trained, however, uptake is low, particularly in rural areas. The product is available over the counter, and has been aggressively promoted in urban areas. Although the MOHFW officially supports universal access to ECP, in practice it has not taken action to support this policy. At the state level, knowledge about ECP is uniformly poor and negative.

\section{Nigeria}

Although modern methods of contraception and emergency contraceptives are available over the counter, use of modern contraceptive methods, including ECP, remains low in Nigeria. The main access point for users of modern contraceptives is the private sector (61 percent), compared with 23 percent in the public sector. Patent medicine vendors and local pharmacists constitute 39 percent and 10 percent, respectively, of the private sources. Younger unmarried women tend to patronize the private sector, whereas older married women typically obtain products through the public sector.

\section{Senegal}

In Senegal, ECP is included in the national family planning program and, in principle, is available for free at public sector facilities. In practice, however, clients purchase ECP at pharmacies at higher prices. ECP provision in the public sector is hampered by a weak health system characterized by poor services, poorly trained providers, intermittent commodity supplies, and poor recordkeeping and data monitoring.

\section{STUDY OBJECTIVE}

The overarching goal of this study was to investigate and document providers' attitudes, beliefs, and practices regarding ECP, and to capture the opinions and insights of providers and KOLs on a range of policy and program issues. In addition, the study sought to experiment with question-asking regarding the concept of "repeat use."

\section{METHODOLOGY}

A mix of quantitative and qualitative methods was used. Through a quantitative survey applied to a representative sample of service providers in each country, the study gathered information on providers' attitudes toward ECP use and users, their level of knowledge and training, their opinions regarding repeat use, and their ECP provision practices. "Provider" was broadly defined to include frontline health workers, midwives, nurses, doctors, pharmacists, patent medicine vendors, and other health staff. Qualitative data gathered through indepth interviews with selected KOLs were combined with provider surveys to give a robust and nuanced picture of the current situation regarding provision of ECP.

Site and sample selection

The study was designed to align with broader urban health initiatives currently underway in each country; thus, urban centers were selected for sampling. The study was conducted in a total of ten urban centers: five in India (Agra, Aligarh, Delhi, Kanpur, and Lucknow), two in Nigeria (Abuja and Kaduna), and three in Senegal (Dakar, Mbour, and Thies).

Using existing sampling frames in each country, a representative sample of providers was drawn from each country. The analysis includes only providers who were currently or had ever provided ECP. 
TABLE 1 Number of interviews conducted, by provider type, according to country

\begin{tabular}{lrrrr}
\hline Provider type & India & Nigeria & Senegal & Total \\
\hline Doctors & 83 & 21 & 10 & 114 \\
Paramedics & 33 & 0 & 0 & 33 \\
Nurse/midwife & 0 & 118 & 85 & 203 \\
Pharmacists & 199 & 146 & 26 & 371 \\
Pharmacy counter staff & 0 & 0 & 30 & 30 \\
Patent medicine vendors & 0 & 122 & 0 & 122 \\
Others & 0 & 0 & 4 & 4 \\
Total & 315 & 407 & 155 & 877 \\
\hline
\end{tabular}

Sixty-six in-depth interviews were conducted across the three countries with purposively sampled KOLs from both the public and private sectors. The interviews capture multiple perspectives that reflect policy, program, service delivery, and civil society positions.

TABLE 2 Number of interviews, by type of KOL, according to country

\begin{tabular}{|c|c|c|c|c|}
\hline $\begin{array}{l}\text { Profile of } \\
\text { key opinion leaders }\end{array}$ & India & Nigeria & Senegal & Total \\
\hline $\begin{array}{l}\text { Government officials/ } \\
\text { decisionmakers at policy } \\
\text { and program levels }\end{array}$ & 8 & 4 & 11 & 23 \\
\hline $\begin{array}{l}\text { Members of professional } \\
\text { associations }\end{array}$ & 7 & 5 & 5 & 17 \\
\hline NGO representatives & 0 & 3 & 3 & 6 \\
\hline $\begin{array}{l}\text { Development part- } \\
\text { ners/donors }\end{array}$ & 3 & 1 & 4 & 8 \\
\hline Manufacturer & 1 & 0 & 0 & 1 \\
\hline Private practitioner & 0 & 0 & 1 & 1 \\
\hline Distributors & 0 & 0 & 3 & 3 \\
\hline $\begin{array}{l}\text { Members of community- } \\
\text { based organizations }\end{array}$ & 0 & 0 & 7 & 7 \\
\hline Total & 19 & 13 & 34 & 66 \\
\hline
\end{tabular}

\section{FINDINGS}

Each country has unique and specific findings which are reported elsewhere (see India, Nigeria, and Senegal briefs). Here we describe overall study results. Although the three countries have vastly different social and political contexts, and are at different stages in the evolution of ECP programming and maturity of family planning programs, the following key themes emerged across sites:

- Gaps exist in providers' knowledge of technical issues, including mechanisms of action, efficacy, and timing of use.

- Wide variation across and within countries exists in levels of training on ECP among different cadres of providers.

- KOLs hold positive views of ECP overall, believing it fills an important niche in the contraceptive method mix.
- Providers' attitudes are mixed concerning provision of ECP to particular populations (e.g., young unmarried women) and in certain contexts.

- Providers and KOLs are generally not supportive of "advance provision" of ECP, because of the underlying assumption that this leads to "abuse" or "over use"; they express concern that women will bypass or abandon "regular contraception" if ECP provision is lenient.

- The majority of providers are unsupportive of "repeat use" and/or "regular use."

- Interpretations and definitions of "repeat use," "regular use," and "frequent use" vary widely; most providers are unable to provide a precise definition.

- KOLs express some caveats about how and where ECP should be distributed, who should provide it, and for which target populations.

As shown in Table 3, the vast majority of providers in the three countries (86-94 percent) consider ECP to be safe, and the majority (60-82 percent) believes

TABLE 3 Percentage of providers expressing various attitudes and beliefs concerning ECP

\begin{tabular}{|c|c|c|c|}
\hline ECP attitude/belief & India & Nigeria & Senegal \\
\hline \multicolumn{4}{|l|}{ Safety } \\
\hline ECP is safe to use & 86 & 94 & 88 \\
\hline \multicolumn{4}{|l|}{ Efficacy } \\
\hline $\begin{array}{l}\text { ECP is very effective in preventing } \\
\text { pregnancy }\end{array}$ & 82 & 66 & 60 \\
\hline \multicolumn{4}{|l|}{ Access } \\
\hline $\begin{array}{l}\text { Women should be provided with } \\
\text { ECP in advance of unprotected sex }\end{array}$ & 55 & 67 & 17 \\
\hline $\begin{array}{l}\text { ECP should be available OTC with- } \\
\text { out prescription }\end{array}$ & 50 & 33 & 41 \\
\hline $\begin{array}{l}\text { There should be no age } \\
\text { restriction on ECP }\end{array}$ & 14 & 14 & 45 \\
\hline \multicolumn{4}{|l|}{ Frequency of use } \\
\hline $\begin{array}{l}\text { There is no maximum number of } \\
\text { times a women can use EC in one } \\
\text { year }\end{array}$ & 64 & 23 & 39 \\
\hline $\begin{array}{l}\text { In one menstrual cycle, EC can be } \\
\text { used after unprotected sex as } \\
\text { needed }\end{array}$ & 15 & 18 & 16 \\
\hline $\begin{array}{l}\text { There should be guidance/ } \\
\text { advice on the frequency of EC } \\
\text { provision for women }\end{array}$ & 44 & 90 & 83 \\
\hline \multicolumn{4}{|l|}{ Acceptable contexts for use } \\
\hline Rape or sexual coercion & 15 & 50 & 93 \\
\hline Infrequent or unpredictable sex & 55 & 20 & 81 \\
\hline Unprotected sex & 23 & 49 & 88 \\
\hline Refugee or conflict settings & 3 & 55 & 54 \\
\hline \multicolumn{4}{|l|}{ Acceptable users } \\
\hline Married women & 67 & 12 & 53 \\
\hline Unmarried adolescents & 42 & 14 & 65 \\
\hline $\mathrm{N}$ & (315) & (407) & (155) \\
\hline
\end{tabular}


that it is effective in preventing pregnancies. With regard to more specific access issues-advance provision, age restrictions, frequency of use-responses become more conservative, and also vary more widely across the three countries. The concept of "repeat use" is one such divisive issue, in part, perhaps, because of the lack of standardization regarding what is meant by the term. For some providers, the threshold for "repeat use" is two or three times per menstrual cycle, whereas for others it is one or two times per year.

\section{PROGRAM AND POLICY IMPLICATIONS}

The identification and amelioration of provider-related barriers is a critical avenue to improve EC access within country programs and globally. Many provider-related barriers can be overcome through implementation of targeted interventions such as training and values clarification, whereas other barriers will require a broader strategy to address contextual and health systems-level factors that hinder women's access to ECP.

Interventions that might prove useful in addressing these barriers include:

- Improving knowledge about ECP among providers and potential users through a variety of channels, including digital and electronic communication, mass media, public aware- ness campaigns, and educational print materials for providers and potential users.

- $\quad$ Evidence-based advocacy targeted to policymakers and donors to garner commitment to both the concept of emergency contraception as well as ECP products, including their integration into family planning programs, processes, and budgets.

- Efforts to reduce the cost of EC products and product delivery. This may include bulk purchasing of commodities, greater competition in the marketplace (with new post coital contraceptive products), and/or negotiation with manufacturers and distributors regarding pricing strategies.

- Operational research on a range of service delivery issues, including bridging ECP with other family planning methods.

- Social science research to better understand the social determinants of demand and use dynamics.

- Support for research and development for post-coital prevention products.

For more information, contact mbrady@popcouncil.org.

The Population Council confronts critical health and development issues-from stopping the spread of HIV to improving reproductive health and ensuring that young people lead full and productive lives. Through biomedical, social science and public health research in about 50 countries, the Council works with our partners to deliver solutions that lead to more effective policies, programs, and technologies to improve lives worldwide. Established in 1952 and headquartered in New York, the Council is a nongovernmental, nonprofit organization with an international board of trustees.

www.popcouncil.org

(C) 2012 The Population Council, Inc.
Population Council, One Dag Hammarskjold Plaza New York, NY 10017 